\section{DRAMATICALLY IMPROVED IMAGES}

Software of Excellence has developed EXAMINE PRO II, a software solution that enables images to be used quickly and easily to enhance chairside explanations. EXAMINE PRO II includes all the regular features from the original EXAMINEPRO, but with a fresh approach and enhanced functionality.

EXAMINE PRO II facilitates the bringing together of all images: digital radiographs, photographs and intra oral images, regardless of their source, into the patient record in EXACT. Integration of images with the patient chart means that relevant thumbnails appear for every tooth, displaying useful information such as image type, date taken, tooth notation and file size. Double clicking the image enlarges it to full size allowing viewing and manipulation to take place as required.

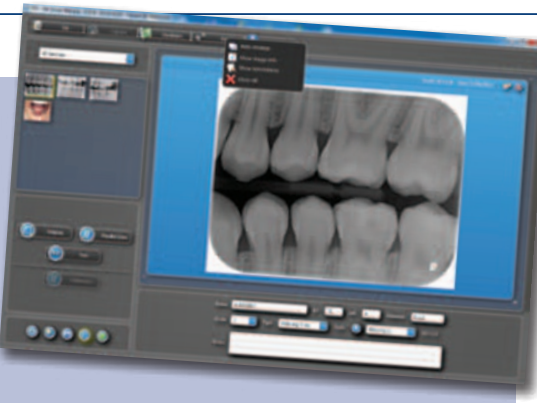

New technology in the software dramatically improves the quality of images using adaptive image processing which increases the contrast and improves the viewable detail in an image, a technique that can be performed quickly and easily from the chairside.

For more information call 08453455767 or visit www. soeidental.com.

\section{MILL, POLISH, STAIN AND FIT}

Dental Innovations are offering two must-have products for any forward-thinking dental practice: CEREC chairside CADCAM and hard and soft tissue laser technology.

The patented scientific Biogeneric design software of CEREC together with the intuitive user guidance allows you to digitally create natural occlusal surfaces for crowns, veneers, inlays, onlays and full anatomical bridges. The digital impression generated by CEREC saves time and can be milled, polished, stained and fitted in surgery in one session, or sent digitally to the laboratory who will then create the full restoration.

Dental Innovations provide solutions for soft and hard
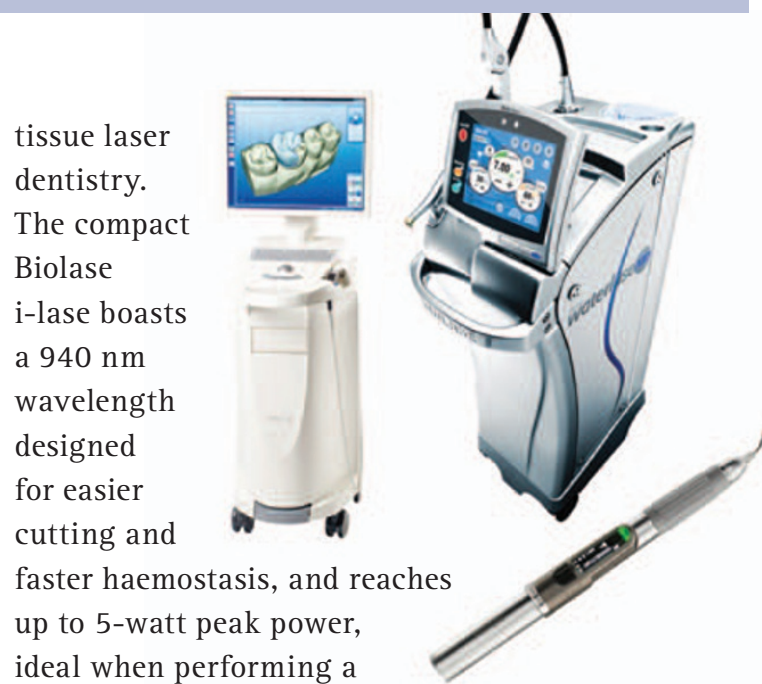

up to 5-watt peak power ideal when performing a

big variety of soft-tissue and hygiene procedures including gingivectomies, implant recovery and crown lengthening. For hard-tissue laser dentistry, the Biolase Waterlase MD effectively combines YSGG laser energy and water to perform a range of procedures with less anaesthesia, reducing patient anxiety and minimising pain. Plus the user can switch from treating hard tissue to soft tissue treatment in seconds.

For more details call 08700102041 or visit www.henryschein.co.uk.

\section{BROWSE TREATMENT} CENTRE 'MOVIES'

When anyone is considering a product purchase that requires a large investment, the Internet can be a crucial element in the decision making process. To satisfy the growing demand for online information, Takara

Belmont have launched their own YouTube channel which features eight glossy short movies. Each film covers key and unique features of leading items within their portfolio. Designed for those that do not have access to showrooms or prefer to browse in their own time, the movies are a new way to evaluate what Takara Belmont has to offer.

Beautifully shot to music, the films cover treatment centres, including the newly launched tbCompass as well as chairs, operating lights and X-ray units.

With a longstanding heritage in the fulfilment of human desire for comfort, Takara Belmont have earned worldwide brand loyalty. The company hope that this new YouTube channel provides an informative resource for dentists.

For additional peace of mind, Takara Belmont offers a FREE five-year extended warranty on all treatment centres, dental units, chairs and operating lights. Proud of their reputation for reliable products, the company feels that offering the extended policy will give customers confidence in the product and offer additional peace of mind.

For full details on their warrant policies, contact Takara Belmont on 02075150333.

\section{RAPID BURST OF AIR AND WATER ACCREDITED}

Philips' Sonicare AirFloss has been accredited by the British Dental Health Foundation.

With its pioneering 'microburst technology', Sonicare AirFloss is designed to make interproximal cleaning easier, while maximising plaque removal between teeth.
Sonicare AirFloss works by producing a rapid burst of air and tiny water droplets - which can reach up to $45 \mathrm{mph}$ - to thoroughly fill the area between teeth and force out the plaque bacteria. This is directed using a nozzle guidance tip which ensures precise, targeted cleaning with no mess.

The AirFloss has an ergonomically designed body which fits compactly into the hand, and is cordless and rechargeable.

www.sonicare.com 